\title{
IT IS A HORRIBLE THING: TO BE THIS YOUNG MAN WAITING ON AGE.
}

\section{Ben Mosher}

It is a horrible thing: to be this young man waiting on age. The old ones so wise; you thrill at flushing rabbits through the moonlit snow. How the branches tremble when safety is reached. How a miniature ridge of snow on the branch becomes a line on the ground which fingers the culprit.

In winter, as a schoolboy you packed your bags. You take the necessary objects; what you have. You sit on a train. There are no garlands to greet you, only a wind that bites even metal; the structure of your father's house squeals and with a whitewash the sky obscures itself and pretends unity with the earth. Is this a statement on your life?

Why are you hiding? What do you wait for? Do you imagine yourself an old man stooping with profound vision? Do you imagine yourself forgotten and refound? You spend time on park benches. The pigeons surround you but you are too poor for bread. Or are you selfish? Or are you scared to appear so lonely you seek the company of birds?

Would you dare step on them; these strutting packages of fat and hollow bone? You kick at them. A young girl passes on roller-skates. You watch her shoulders and back. You watch the back of her thighs. Somewhere down the sidewalk her skates hit cobblestone and she tumbles.

You - pretending to watch the trees but really seeing the branch, the way it curves softly like your schoolteacher's arm when she points and her breasts fall away; admiring the bark as rough as your father's beard on your face; how you desire that arm, how you desire to be scratched on your cheek and chin - you're dangerous. You've fallen in love with everyone you've ever met, but are glad you're not them. Around you the pigeons return to the stone beneath your seat, to the crumbs and popcorn left by old men. 